\title{
A Three-Layer Supply Chain EPQ Model for Price- and Stock-Dependent Stochastic Demand with Imperfect Item Under Rework

\author{
Shilpi Pal ${ }^{1 *}$, G. S. Mahapatra ${ }^{2}$ and G. P. Samanta ${ }^{3}$
}

\section{*Correspondence:}

shilpi88pal@gmail.com

'Department of Mathematics,

Techno India University, West

Bengal, India

Full list of author information is

available at the end of the article

\begin{abstract}
In this paper, we have developed an integrated supplier-manufacturer-retailer, joint economic lot-sizing model for the items with stochastic demand and imperfect quality. The supplier produces the item (raw material) up to certain time, which is a decision variable, and sends it to the manufacturer. Now, the manufacturer produces the item in small cycles and the production process of manufacturer is imperfect which produces certain number of defective items. A $100 \%$ screening process for detecting the imperfect quality items is conducted, and at the end of each cycle, the imperfect items are accumulated and are reworked by the manufacturer. Thus, ultimately the retailer receives the perfect quality item. We consider that the delivery quantity to the retailer depends on the price and stock-dependent stochastic demand of the retailer. The model considers the impact of business strategies such as optimal time, optimal ordering size of raw material, production rate, etc. in different sectors on collaborating marketing system. An analytical method is applied to optimize the production time and production rate to obtain minimum total cost. Finally, numerical results, which have several interesting managerial insights and implications, and the sensitivity analysis are presented and discussed for illustrative purposes.
\end{abstract}

Keywords: Supply chain model, Imperfect item, Price- and stock-dependent stochastic demand, Idle time

\section{Introduction}

Supply chain management has taken a very important and critical role for any company, with increasing globalization and competition in the market. A supply chain model (SCM) is a network of suppliers, producers (i.e., manufacturer), distributors (i.e., retailers), and customers which synchronizes a series of interrelated business processes. Nowadays, managers consider this type of modelling in order to obtain (1) optimum of raw materials from nature and then transporting it to a warehouse, (2) optimum production of goods in the production centre and distribution of these finished goods to retailers for sale to the customers. Thus, the researchers are focussing on the supply chain since the success of a firm may depend on its ability to link supply chain members consistently. Thus, integrated inventory management has recently received a great deal of attention. Goyal [12] considered the joint optimization problem of a single vendor and single buyer, in which he assumed that the vendor production rate is infinite. Goyal [13] extended the work by

(c) The Author(s), 2016 Open Access This article is distributed under the terms of the Creative Commons Attribution 4.0 International License (http://creativecommons.org/licenses/by/4.0/), which permits unrestricted use, distribution, and reproduction in any medium, provided you give appropriate credit to the original author(s) and the source, provide a link to the Creative Commons license, and indicate if changes were made. 
one vendor and multi-buyer integrated model where the shipment size increases geometrically. Hill [17] then generalized the model by considering the geometric growth factor as decision variable. Ramakrishna et al. [37] worked with a two-item and two-warehouse model with transhipment. Ben-Daya and Al-Nassar [3] worked on a three-layer supply chain integrated inventory production system. The work has been extended by Ben-Daya et al. [4]. Dellaert and Melo [9] worded on heuristic procedures for a stochastic lot-sizing problem in make-to-order manufacturing. Zhou and Guan [51] worked with two-stage stochastic lot-sizing problem under cost uncertainty. Liberopoulos et al. [27] worked with same type problem but for non-stop multi-grade production with sequence-restricted setup changeovers. Jha and Shanker [22] considered single vendor multiple buyer integrated production model with controlled lead time and service level constraints. The single-vendor multi-buyer integrated inventory supply chain in meeting deterministic demand has received a considerable attention of the researchers (namely, Lam and Ip [25], Hoque [18], Sarkar and Diponegoro [42], Zavanella and Zanoni [49, 50]; Srinivas and Rao [46], Solyal and Sural [44], Ben-Daya et al. [5], Jana et al. [21], Huang et al. [19], Pasandideh et al. [35], Pasandideh et al. [34], Lieckens and Vandaele [28], etc.).

The classical EPQ model assumes that the manufacturing process is failure free and all the items produced are of perfect quality throughout. However, in real production environment, it is observed that the defective items are produced due to imperfect production processes. Thus the inventory policy determined by the conventional model is inappropriate. So, the defective items must be rejected, repaired and reworked, and the corresponding substantial costs is incurred in the integrated total costing of the inventory system. Recently, numerous researchers are working on EPQ/EOQ models with imperfect quality items. This was triggered by Salameh and Jaber [38]. They developed an EOQ model to determine the optimal lot size where each lot delivered by the supplier contains imperfect items with a known probability density function. Hayek and Salameh [15] studied an EPQ model with the reworking of imperfect quality items. El-Kassar [10] examined an EOQ model with imperfect quality items, where the imperfect quality items are sold at a discounted price and the demands for both perfect and imperfect quality items are continuous during the inventory cycle. Chiu [8] considered an EPQ model with random defective rate, a reworking process, and backlogging. Liao and Sheu [26] described an integrated EPQ model with maintenance programs. An EPQ model with raw material of imperfect quality are used for production of finished item was studied by El-Kassar et al. [11]. Sana [39] investigated an EPL (economic production lot size) model in an imperfect production system in which the production facility could shift from an "in-control" state to an "out-of-control" state by and random time. Lin et al. [30] we propose an integrated supplier-retailer inventory model in which both supplier and retailer have adopted trade credit policies, and the retailer receives an arriving lot containing some defective items. Some recent works on inventory models with imperfect quality items is done by many researchers like Sana [40], Khan et al. [23], Soni and Patel [45], and Jaber et al. [20], etc.

Uncertainty plays a important role in most inventory management situations. The retailer wants enough supply to satisfy customer demands, but too much ordering increases holding costs and the risk of losses through obsolescence or spoilage. Also, too small order increases the risk of lost sales and unsatisfied customers. Thus the operations manager has to sets a master production schedule where he has to forecasts the imprecise 
nature of demands and optimize the quantity and manufacturing time to obtain maximum profit. Many work has been done by the researchers using deterministic condition. Pal et al. [33] worked with price and stock depended demand for deteriorating items. (Sarkar and Sarkar [43], Prasad and Mukherjee [36], etc.) worked on stock-dependent demand for deteriorating items and with partial backlogging. Thus in classical EOQ model the researchers works with deterministic approach and analyzed the inventory system which is not satisfactory when uncertainty is present. Nowadays researchers are working with uncertainty in demand, in production process and production time, in lead time, etc. Browne and Paul [6] concerned with the (r, q) inventory model, where demand accumulates continuously, but the demand rate at each instant is determined by an underlying stochastic process. Gumus and Guneri [14] worked on multi inventory stochastic and fuzzy supply chain. Manna et al. [31] worked with three layer supply chain model in fuzzy environment. Kumar et al. [24] worked on economic production lot size model with stochastic demand and shortage partial backlogging rate under imperfect quality items. Sana [41] developed an model for stochastic demand for limited capacity of own warehouse. Pal et al. [32] developed an EPQ inventory model to determine the optimal buffer inventory for stochastic demand in the market during preventive maintenance or repair of a manufacturing facility with an imperfect production system. Alshamrani [2] considers a stochastic optimal control of an inventory model with a deterministic rate of deteriorating items. Abdelsalam and Elassal [1] extended the work of Ben-Daya et al. [5] by relaxing the assumption of deterministic demand and constant holding cost and considering stochastic demand with varying ordering and holding cost. Lin and Wu [29] developed a model with combined pricing and supply chain operations under price-dependent Stochastic demand. He et al. [16] also worked on coordinating a supply chain with price dependent Stochastic demand. Now a days researchers (like Ting and Chung [47], Varyani et al. [48], Chen and Geunes [7], etc.) are considering various parameters as stochastic variable.

Nowadays, few researchers are paying focus on the effect of considering the idle time cost. Time management is extremely important in any business. This includes timing the completion of one project to coordinate with the beginning of another to reduce idle time. Idle time is the time associated with waiting, or when a piece of machinery is not being used but could be. To avoid any machinery or any other failure, sometime during the idle time, the parties (supplier and manufacture) repair and maintain the machineries and can train the worker. Also, too much of idle time means wastage of resources because machinery are idle and it is not in use. Thus, the manager has to optimize the time so that it does not effect the inventory system.

The purpose of this paper is to develop an integrated supplier-manufacturer-retailer production inventory model with imperfect product quality, price and stock-dependent stochastic demand. Deterioration is taken as constant and also the concept of idle time is taken under consideration. The imperfect items are reworked. The shipment of the item is done according to the need of the retailer which in turn depends upon the demand of the customer. The rest of the paper is organized with illustration of notations and assumptions used in the paper. Further the development of the mathematical formulation of this model has been depicted that integrates the supplier - manufacturer - retailer annual cost and takes under the consideration of imperfect production process and rework of the imperfect products. We have also constructed a numerical example using which the 
sensitivity analysis of various parameters are illustrated. Further we also have observed the supply demand relationship. Finally, we summarize and conclude the paper and provide directions for future research.

\section{Assumptions}

Notation:

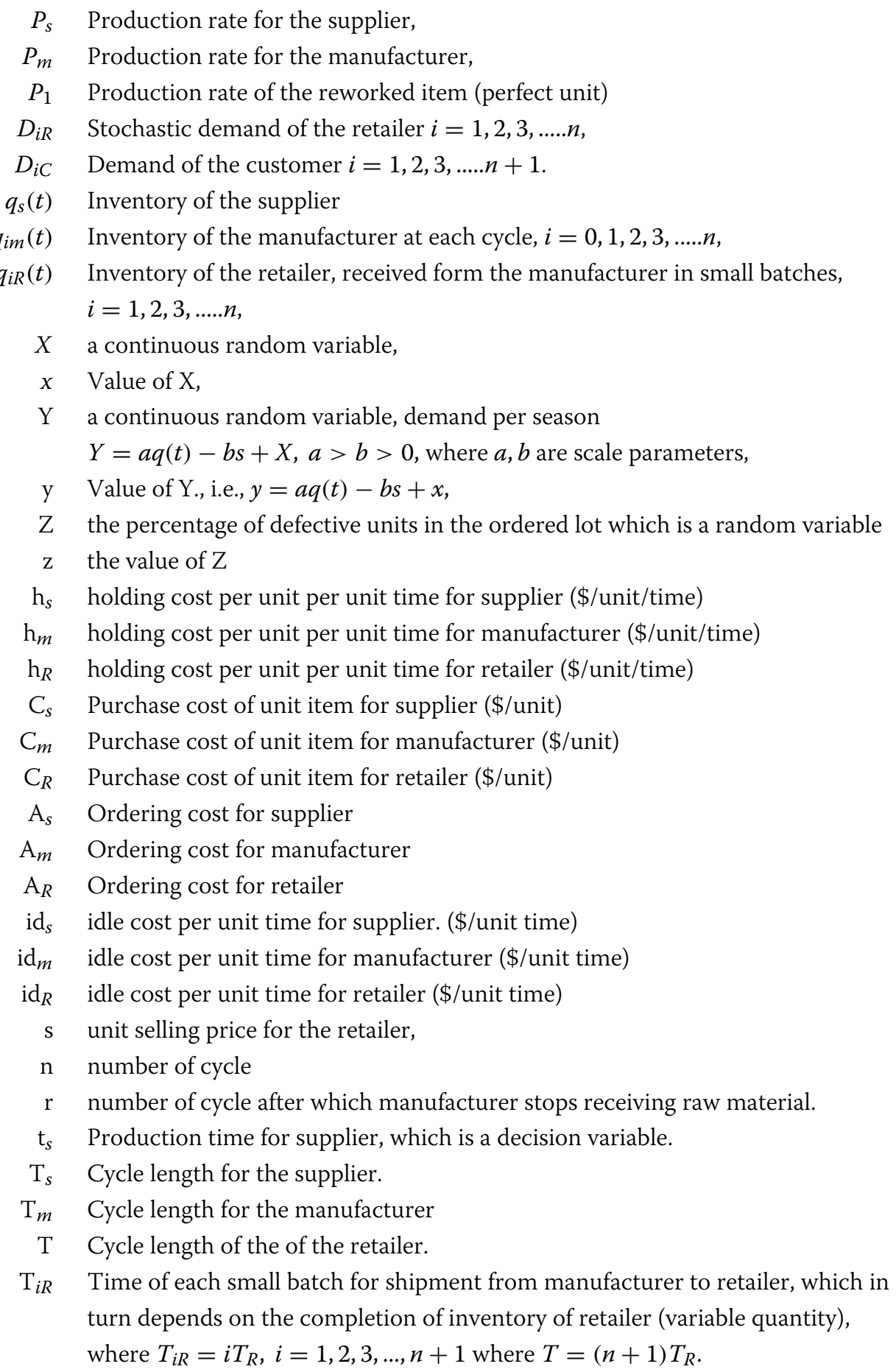




\section{Assumptions:}

1. Demand is price and stock-dependent stochastic, so demand per season is Y, i.e. $D_{i R}=D_{i C}=a q_{i R}(t)-b s+x$.

2. Let the probability density function $f(x)$ of the demand $x$ is,

$$
\begin{aligned}
f(x) & =\lambda e^{-\lambda x} \text { where } 0 \leq x \leq \infty \\
& =0 \quad \text { elsewhere }
\end{aligned}
$$

which is a exponential distribution function where $\lambda$ is the parameter of distribution.

3. Consider the probability density function $\mathrm{g}(\mathrm{z})$ for the rate of defective item $\mathrm{z}$

$$
\begin{aligned}
g(z) & =\frac{\theta}{1-e^{-\theta}} e^{-\theta} \text { where } 0 \leq z \leq 1, \theta>0 \\
& =0 \text { elsewhere }
\end{aligned}
$$

this is truncated exponential distribution where $\theta$ is the parameter of distribution.

4. Production rate of manufacturer is more than demand of manufacturer (because there are defective item, which are produced by the manufacturer, and are reworked and thereby finally good items are sent to retailer. So, to overcome the shortage from manufacturer end point more inventory is produced).

5. Lead time is negligible.

6. Inventory system is for a single item.

7. Defective item that are produced by the manufacturer are reworked and produced at the rate $P_{1}$.

8. Continuous shipment if quantity from supplier to manufacturer.

9. Idle time for supplier, manufacturer and retailer are also assumed. It is the time when the machine is idle and we have assumed that there is no failure in machinery at any point of time.

10. Their is no deterioration at retailer's end and hence no shortage at retailer end.

11. Item gets produced in the required time and supplier supplies continuously to manufacture which in turn supplies to retailer in batches and so it starts one cycle before the retailer.

12. At $i T_{R}$ point of time (i.e., at regular interval of time), retailer determines the demand rate and orders that amount from the manufacturer, where $i=1,2,3 \ldots . n$.

13. To optimize the production cycle from manufacturer end we assume that until and unless sufficient quantity of the raw material is not available from supplier end then we will not run the cycle of manufacturer. Thus, for simplicity we assume that time when supplier end its inventory, manufacturer stops producing item and from that time onward manufacturer will only supply to the retailer as per their requirement.

\section{Mathematical Model}

We considered three stage joint economic lot sizing model for a supply chain problem with single supplier, single manufacturer and single retailer. The supplier produces and sends its finished goods to the manufacturer which is used as a raw material for the manufacturer. The manufacturer produces the item in small cycles which includes imperfect items also. At the end of each cycle the imperfect items are accumulated and it is reworked by the manufacturer. Thus, ultimately the retailer receives the perfect quality item. The 
demand of the retailer is price and stock depended stochastic demand which depends on the customer's choice. The amount of shipment from manufacturer to retailer depends on retailer's demand which in turn depends on customer's demand.

\section{Formulation of Supplier Individual Cost}

The integrated inventory model (Fig. 1) starts when $t=0$ and stock is also zero. At that time, the supplier starts their production with the rate $P_{s}$ unit per unit time and supply it to the manufacturer simultaneously. When $t=t_{s}$, suppliers stop their production, and at $t=T_{s}$, the inventory level of the supplier becomes zero. The total time of the integrated model is $\mathrm{T}$, so the idle time for supplier is $T-T_{s}$.

$$
\frac{d q_{s}}{d t}= \begin{cases}P_{s}-P_{m} & \text { for } 0 \leq t \leq t_{s} \\ -P_{m} & \text { for } t_{s} \leq t \leq T_{s} \\ 0 & \text { for } T_{s} \leq t \leq T\end{cases}
$$

Along with the boundary conditions, $q_{s}(0)=0, \quad q_{s}\left(t_{s}\right)=Q_{s}, \quad q_{s}\left(T_{s}\right)=0$.

Thus, using boundary condition and solving equation no. (1) we get,

$$
q_{s}(t)=\left\{\begin{array}{cl}
\left(P_{s}-P_{m}\right) t & \text { for } 0 \leq t \leq t_{s} \\
P_{m}\left(T_{s}-t\right) & \text { for } t_{s} \leq t \leq T_{s} \\
0 & \text { for } T_{s} \leq t \leq T
\end{array}\right.
$$

Equating the Eq. (2) we get, time when supplier finishes it item $=T_{s}=\frac{k P_{s}}{P_{m}} t_{s}$ (where $k>0$ is a scale parameter)

Now since $k P_{s} t_{s}=P_{m} T_{r R}=r P_{m} T_{R}$, so, $T_{R}=\frac{k P_{s}}{P_{m} r} t_{s}$

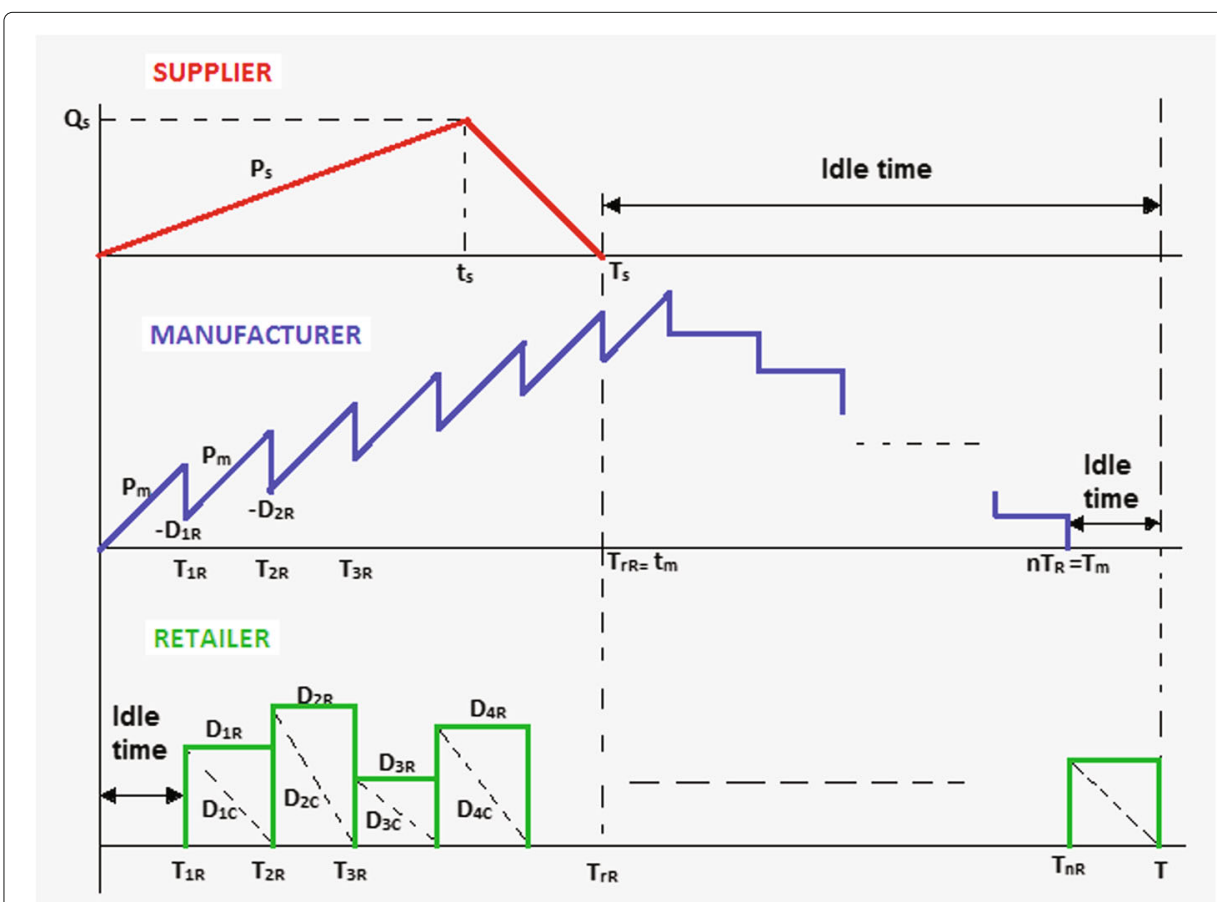

Fig. 1 Graphical representation of the three layer supply chain model 
Holding cost for the supplier $\left(H C_{S}\right)$

$$
H C_{s}=h_{s}\left[\int_{0}^{t_{s}}\left(P_{s}-P_{m}\right) t d t+\int_{t_{s}}^{T_{s}} P_{m}\left(T_{s}-t\right) d t\right]=\frac{h_{s}}{2}\left[\frac{P_{s}^{2} t_{s}^{2}}{P_{m}}-P_{s} t_{s}^{2}\right]
$$

Idle time for supplier $(I D T)=T-T_{s}=(n+1) T_{R}-T_{s}=\left(\frac{n+1}{r}-1\right) \frac{k P_{s}}{P_{m}} t_{s}$

Idle time cost $=\left(I D C_{s}\right)=i d_{s}(I D T)=i d_{s}\left(\frac{n+1}{r}-1\right) \frac{k P_{s}}{P_{m}} t_{s}$

Purchase cost of supplier $=\left(P C_{s}\right)=C_{s} P_{s} t_{s}$

Ordering cost $\left(O C_{s}\right)=A_{s}$

Therefore Total cost of manufacturer $=T C_{s}=H C_{s}+I D C_{s}+P C_{s}+O C_{s}$

$$
=\frac{h_{s}}{2}\left[\frac{P_{s}^{2} t_{s}^{2}}{P_{m}}-P_{s} t_{s}^{2}\right]+i d_{s}\left(\frac{n+1}{r}-1\right) \frac{k P_{s}}{P_{m}} t_{s}+C_{s} P_{s} t_{s}+A_{s}
$$

\section{Formulation of Manufacturer Individual Cost}

The manufacturers start their production at the time $t=0$ when the production rate $P_{m}$ unit per unit time supply it to the retailer at the rate $D_{i R}$ depending upon the demand of the customer $D_{i C}$. At the time $t=T_{s}=T_{r R}$, manufacturer stops receiving raw material from the supplier and thus stop producing the finished good. But, during $\left[T_{r R}, T_{(r+1) R}\right]$, the manufacturer rework on the imperfect item to make a perfect finished item. At the time $t=T_{m}=T_{n R}$, the stock of the manufacturer is zero. Thus, the idle time for the manufacturer is $T-n T_{R}$.

$$
\frac{d q_{m}}{d t}=\left\{\begin{array}{c}
(1-z) P_{m}, 0 \leq t \leq T_{R} \quad \text { where } q_{m}(0)=0 \\
(1-z) P_{m}+z P_{1}, \quad i T_{R} \leq i \leq(i+1) T_{R} \text { where } i=1,2,3, \ldots ., r \\
\quad \text { and } q_{i m}\left(i T_{R}+0\right)=q_{(i-1) m}\left(i T_{R}\right)-D i_{R} \\
z P_{1}, r T_{R} \leq t \leq(r+1) T_{R}, \quad \text { where } q_{m}\left(r T_{R}\right)=q_{m}\left(r T_{R}\right)-D_{r R}
\end{array}\right.
$$

And

$$
q_{i m}(t)=\left\{\begin{array}{cc}
q_{r m}\left[(r+1) T_{R}\right]-\sum_{K=r}^{i} D_{K R}, & i T_{R} \leq t \leq(i+1) T_{R} \text { where } i=r+1, \ldots, n-1 \\
0 & \left(i . e ., t_{m} \leq t \leq T_{m}\right) \\
n T_{R}<t<T
\end{array}\right.
$$

Thus, using boundary condition and solving Eq. (4) and simplifying Eq. (5) we get,

$$
q_{m}(t)=\left\{\begin{array}{l}
(1-z) P_{m} t, \quad 0 \leq t \leq T_{R}, \text { where } q_{m}(0)=0 \\
(1-z) P_{m} t+z P_{1}\left(t-T_{R}\right)-\frac{T_{R}(x-b s) i(i+1)}{2}\left[1+\frac{a T_{R}(2 i+1)}{3}\right], i T_{R} \leq i \leq(i+1) T_{R} \text { where } i=1,2,3, \ldots, r \\
z P_{1}\left(t-T_{R}\right)+r T_{R}\left\{(1-z) P_{m}-(x-b s)\left[\frac{r+1}{2}+\frac{a T_{R}\left(2 r^{2}+3 r+1\right)}{6}\right]\right\}, r T_{R} \leq t \leq(r+1) T_{R}, \\
T_{R}(x-b s) \frac{(i-r)}{6}\left[3(i+r+1)+a T_{R}\left[(i+r+1)^{2}+i(i+1)+r(r+1)\right]\right], i T_{R} \leq t \leq(i+1) T_{R} \\
\quad n \quad \text { where } i=r+1, \ldots, n-1\left(i . e ., t_{m} \leq t \leq T_{m}\right) \\
\quad n T_{R}<t<(n+) T_{R}=T
\end{array}\right.
$$

Holding cost for manufacturer $\left(H C_{M}\right)$ is

$$
\begin{aligned}
H C_{M}=h_{m} & {\left[\int _ { 0 } ^ { 1 } \left(\int _ { 0 } ^ { q } \left\{\int_{0}^{T_{R}} q_{m}(t) d t+\sum_{i=1}^{r-1} \int_{i T_{R}}^{(i+1) T_{R}} q_{m}(t) d t+\int_{r T_{R}}^{(r+1) T_{R}} q_{m}(t) d t\right.\right.\right.} \\
& \left.\left.\left.+\sum_{i=r+1}^{n} \int_{i T_{R}}^{(i+1) T_{R}} q_{m}(t) d t\right\} f(x) d x\right) g(z) d z\right]
\end{aligned}
$$


In the inventory system, the demand follows a special type of probabilistic density function $\mathrm{f}(\mathrm{x})$ as:

$$
f(x)=\left\{\begin{array}{rc}
\lambda e^{-\lambda x} & \text { where } 0 \leq x \leq \infty \\
0 & \text { elsewhere }
\end{array}\right.
$$

Also the rate of defective item follows the probability density function $g(z)$ as:

$$
g(z)=\left\{\begin{array}{ccc}
\frac{\theta}{1-e^{-\theta}} & e^{-\theta} & \text { where } 0 \leq z \leq 1, \theta>0 \\
& 0 & \text { elsewhere }
\end{array}\right.
$$

Thus Holding cost for manufacturer is

$$
\begin{aligned}
& H C_{M}=\frac{h_{m} \theta}{1-e^{-\theta}} {\left[\left(\alpha+\frac{1}{\lambda}-\xi_{1}-b \xi_{2} s\right)\left(\frac{e^{-\lambda \beta-\theta}-e^{-\lambda \alpha}}{\alpha \lambda-\beta \lambda-\theta}\right)+\left(\frac{1}{\lambda}-\xi_{1}-b \xi_{2} s\right)\left(\frac{e^{-\theta}-1}{\theta}\right)\right.} \\
&\left.+\xi_{3}\left(\frac{e^{-\theta}}{\theta}+\frac{e^{-\theta}}{\theta^{2}}-\frac{1}{\theta^{2}}\right)-\left(\xi_{3}+\beta-\alpha\right)\left(\frac{e^{-\lambda \beta-\theta}}{\alpha \lambda-\beta \lambda-\theta}+\frac{e^{-\lambda \beta-\theta}-e^{-\alpha \lambda}}{(\alpha \lambda-\beta \lambda-\theta)^{2}}\right)\right]
\end{aligned}
$$

where

$$
\begin{aligned}
& q=(1-z) P_{m} t_{m}+z P_{1} T_{(r+1) R} \text { where } t_{m}=T_{r R} . \\
& \alpha=P_{m} t_{m}=P_{m} r T_{R} \\
& \beta=(r+1) P_{1} T_{R} \\
& \xi_{1}=\frac{P_{m} T_{R}^{2}}{2}+\frac{P_{m} T_{R}^{2}}{2}\left(r^{2}-1\right)+r P_{m} T_{R}^{2}+(n-r) r T_{R} P_{m} \\
& \xi_{2}=\left[\frac{\left(r^{2}-1\right)\left(a r T_{R}+2\right) T_{R}}{12}+\frac{(r+1) T_{R}}{2}+\frac{a T_{R}^{2}(2 r+1)(r+1)}{6}+\frac{(r+1) r(n-r)}{2}\right. \\
& \left.\times\left(1+\frac{a T_{R}(2 r+1)}{3}\right)+\xi_{4}\right] T_{R} \\
& \xi_{3}=\left[\xi_{1}-\frac{P_{1} T_{R}^{2} r^{2}}{2}-(n-r) r P_{1} T_{R}\right] \\
& \xi_{4}=\frac{1}{6}\left[a T_{R}\left\{\frac{n^{2}(n+1)^{2}}{2}-\frac{(r+1)^{2}(r+2)^{2}}{2}\right\}+\left(3+r-a r T_{R}\right)\right. \\
& \times\left[\frac{n(n+1)(2 n+1)}{3}-\frac{(r+1)(r+2)(2 r+3)}{3}\right] \\
& +\left[(r+1)\left(3+a T_{R}(2 r+1)\right)-2 r(r+3)\right]\left[\frac{n(n+1)}{2}-\frac{(r+1)(r+2)}{2}\right] \\
& \left.-r(n-r)(r+1)\left(3+a T_{R}(2 r+1)\right)\right]
\end{aligned}
$$

Total idle cost $\left(I D C_{M}\right)=i d_{m}\left(T-n T_{R}\right)=i d_{m} T_{R}=i d_{m} \frac{k P_{s}}{P_{m}} t_{s}$ Purchase cost $\left(P C_{M}\right)=C_{m} P_{m} T_{S}=C_{m} k P_{s} t_{s}$ Ordering cost $\left(O C_{M}\right)=A_{m}$ 
Therefore, total cost of manufacturer

$$
\begin{aligned}
T C_{M}= & H C_{M}+I D C_{M}+P C_{M}+O C_{M} \\
= & \frac{h_{m} \theta}{1-e^{-\theta}}\left[\left(\alpha+\frac{1}{\lambda}-\xi_{1}-b \xi_{2} s\right)\left(\frac{e^{-\lambda \beta-\theta}-e^{-\lambda \alpha}}{\alpha \lambda-\beta \lambda-\theta}\right)+\left(\frac{1}{\lambda}-\xi_{1}-b \xi_{2} s\right)\right. \\
& \times\left(\frac{e^{-\theta}-1}{\theta}\right)+\xi_{3}\left(\frac{e^{-\theta}}{\theta}+\frac{e^{-\theta}}{\theta^{2}}-\frac{1}{\theta^{2}}\right) \\
& \left.-\left(\xi_{3}+\beta-\alpha\right)\left(\frac{e^{-\lambda \beta-\theta}}{\alpha \lambda-\beta \lambda-\theta}+\frac{e^{-\lambda \beta-\theta}-e^{-\alpha \lambda}}{(\alpha \lambda-\beta \lambda-\theta)^{2}}\right)\right] \\
& +i d_{m} \frac{k P_{s}}{P_{m}} t_{s}+C_{s} P_{m} k T_{S}+A_{m}
\end{aligned}
$$

where $\xi_{1}, \xi_{2}, \xi_{3}, \alpha, \beta$ are mentioned above.

\section{Formulation of Retailer Individual Cost}

The retailer starts selling this product to the customer at the time $t=T_{R}$ and end selling at $t=(n+1) T_{R}$ according to the demand of the customer. The idle period for retailer is $\left[0, T_{R}\right]$.

$$
\frac{d q_{i R}(t)}{d t}=-D_{i C}=-D_{i R}, \quad i=1,2,3, \ldots ., n, \text { where } q_{i R}\left(T_{i R}\right)=D_{i R} T_{i R}
$$

Thus thus using boundary condition and solving and simplifying Eq. (8), we get

$$
q_{i R}(t)=(x-b s)\left[\frac{2 T_{i R}-t}{1-a T_{i R}}\right], \quad i=1,2,3, \ldots ., n
$$

Holding cost of retailer

$$
\begin{aligned}
H C_{R}=h_{R}\left[\int_{0}^{1}\right. & \left.\left(\int_{0}^{q}\left\{\sum_{i=1}^{n} \int_{i T_{R}}^{(i+1) T_{R}} q_{i R}(t) d t\right\} f(x) d(x)\right) g(z) d z\right] \\
=\frac{h_{R} \theta \eta_{1}}{1-e^{-\theta}} & {\left[\left(\frac{1}{\lambda^{2}}-\frac{b s}{\lambda}\right)\left(\frac{e^{-\theta}-1}{\theta}-\frac{e^{-\lambda \beta-\theta}-e^{-\lambda \alpha}}{\alpha \lambda-\beta \lambda-\theta}\right)-\frac{\beta e^{-\lambda \beta-\theta}-\alpha e^{-\lambda \alpha}}{\lambda(\alpha \lambda-\beta \lambda-\theta)}\right.} \\
& \left.-\frac{(\alpha-\beta)\left(e^{-\lambda \beta-\theta}-e^{-\lambda \alpha}\right)}{(\alpha \lambda-\beta \lambda-\theta)^{2}}\right]
\end{aligned}
$$

where $\eta_{1}=\left(\frac{T_{R}^{2} n^{2}}{2}-\frac{a T_{R}^{3} n\left(n^{2}-1\right)}{3}\right) \lambda$ and $f(x)$ and $g(z)$ is define above.

Total idle cost $\left(I D C_{R}\right)=i d_{R} T_{R}$

Since retailer receives perfect quality from the manufacturer, thus the retailer has to purchase.

$$
\begin{aligned}
& \text { Purchase cost }\left(P C_{R}\right)=C_{R}\left[\int_{0}^{1}\left(\int_{0}^{q}\left\{\sum_{i=1}^{n} q_{i R}\left(T_{i R}\right)\right\} f(x) d(x)\right) g(z) d z\right]= \\
&=\frac{c_{R} T_{R} \theta n(n+1)}{2\left(1-e^{-\theta}\right)}\left(1+\frac{a T_{R}(2 n+1)}{3}\right) {\left[\frac{\lambda \alpha-1}{\lambda(\lambda \alpha-\lambda \beta-\theta)}\left(e^{-\lambda \beta-\theta}-e^{-\alpha \lambda}\right)-\frac{1}{\theta \lambda}\left(e^{-\theta}-1\right)\right.} \\
&\left.-(\alpha-\beta)\left[e^{-\lambda \beta-\theta}-\frac{\left(e^{-\lambda \beta-\theta}-e^{-\alpha \lambda}\right)}{\lambda(\lambda \alpha-\lambda \beta-\theta)^{2}}\right]\right]
\end{aligned}
$$

Ordering cost $\left(O C_{r}\right)=A_{R}$ 
Therefore, total cost of retailer $T C_{R}=H C_{R}+I D C_{R}+P C_{R}+O C_{R}$

$$
\begin{aligned}
=\frac{h_{R} \theta \eta_{1}}{1-e^{-\theta}} & {\left[\left(\frac{1}{\lambda^{2}}-\frac{b s}{\lambda}\right)\left(\frac{e^{-\theta}-1}{\theta}-\frac{e^{-\lambda \beta-\theta}-e^{-\lambda \alpha}}{\alpha \lambda-\beta \lambda-\theta}\right)-\frac{\beta e^{-\lambda \beta-\theta}-\alpha e^{-\lambda \alpha}}{\lambda(\alpha \lambda-\beta \lambda-\theta)}\right.} \\
& \left.-\frac{(\alpha-\beta)\left(e^{-\lambda \beta-\theta}-e^{-\lambda \alpha}\right)}{(\alpha \lambda-\beta \lambda-\theta)^{2}}\right] \\
& +i d_{R} T_{R}+\frac{c_{R} T_{R} \theta n(n+1)}{2\left(1-e^{-\theta}\right)}\left(1+\frac{a T_{R}(2 n+1)}{3}\right)\left[\frac{\lambda \alpha-1}{\lambda(\lambda \alpha-\lambda \beta-\theta)}\left(e^{-\lambda \beta-\theta}-e^{-\alpha \lambda}\right)\right. \\
& \left.-\frac{1}{\theta \lambda}\left(e^{-\theta}-1\right)-(\alpha-\beta)\left[e^{-\lambda \beta-\theta}-\frac{\left(e^{-\lambda \beta-\theta}-e^{-\alpha \lambda}\right)}{\lambda(\lambda \alpha-\lambda \beta-\theta)^{2}}\right]\right]+A_{R}
\end{aligned}
$$

Therefore, the total costing of the inventory is $T C=T C_{s}+T C_{M}+T C_{R}$.

We have considered two cases: case 1 we optimize the total cost with respect to production cycle time of supplier $\left(\mathrm{t}_{s}\right)$ while in case 2 we optimize the total cost with respect to production rate of the supplier $\left(\mathrm{P}_{s}\right)$.

Case 1 Production cycle time of supplier $\left(t_{s}\right)$ is the decision variable.

Lemma $1 T C\left(t_{s}\right)$ has a global minimum for $t_{s} \in[0, \infty)$ provided all three conditions are satisfied

(i) $P_{s}>P_{m}$

(ii) $r n^{2} T_{s}+\frac{a r C_{r} n(1+n)(1+2 n) P_{s}^{2} \theta \sigma}{3\left(1-e^{-\theta}\right) P_{m}^{2}}>2 a n\left(n^{2}-1\right) P_{s} t_{s} \varphi$

(iii) $\frac{d^{2} T C_{m}}{d t_{s}^{2}}>0$

Proof As the total cost TC is function of $\mathrm{t}_{s}$ so we have to minimize the total cost and obtain the optimum value of the production time for supplier taken is $t_{s}^{*}$. If $\frac{d T C}{d t_{s}}$ exits for $t_{s} \in[0, \infty)$ then the necessary condition for $T C\left(t_{s}\right)$ to be minimized is $\frac{d T C}{d t_{s}}=0$ and thus obtain the point $t_{s}=t_{s}^{*}$. Thus the optimal value of $t_{s}^{*}$ is such that $T C\left(t_{s}\right)$ has the minimum value if the derived value $T C^{*}\left(t_{s}^{*}\right)$ must satisfy the sufficient condition, $\left.\frac{d^{2} T C}{d t_{s}^{2}}\right|_{t_{s}=t_{s}^{*}}>0$

Now, let us check the sufficient condition: $\frac{d^{2} T C}{d t_{s}^{2}}=\frac{d^{2} T C_{s}}{d t_{s}^{2}}+\frac{d^{2} T C_{m}}{d t_{s}^{2}}+\frac{d^{2} T C_{R}}{d t_{s}^{2}}$ at the point $t_{s}=t_{s}^{*} \frac{d^{2} T C_{s}}{d t_{s}^{2}}=h_{s}\left[\frac{P_{s}^{2}}{P_{m}}-P_{s}\right]>0$ (from condition (i) i.e., $P_{s}>P_{m}$ ) $\frac{d^{2} T C_{R}}{d t_{s}^{2}}=\frac{n^{2} P_{s}^{2}}{P_{m}^{2} r^{2}}+$ $\frac{a C_{r} n(1+n)(1+2 n) P_{s}^{4} \theta \sigma}{3\left(1-e^{-\theta}\right) P_{m}^{4} r^{2}}-\frac{2 a n\left(n^{2}-1\right) P_{s}^{3} t_{s} \lambda \varphi}{P_{m}^{3} r^{3}}>0$ (from condition (ii) and $\frac{d^{2} T C_{m}}{d t_{s}^{2}}>0$

Thus,

$$
\begin{aligned}
\frac{d^{2} T C}{d t_{s}^{2}}=h_{s} & {\left[\frac{P_{s}^{2}}{P_{m}}-P_{s}\right]+\frac{h_{m} \theta}{1-e^{-\theta}}\left[\left(-\frac{d^{2} \xi_{1}}{d t_{s}^{2}}-b s \frac{d^{2} \xi_{2}}{d t_{s}^{2}}\right)\left(\frac{e^{-\lambda \beta-\theta}-e^{-\lambda \alpha}}{\alpha \lambda-\beta \lambda-\theta}\right)\right.} \\
& +\left(-\frac{d^{2} \xi_{1}}{d t_{s}^{2}}-b s \frac{d^{2} \xi_{2}}{d t_{s}^{2}}\right)\left(\frac{e^{-\theta}-1}{\theta}\right)+\frac{d^{2} \xi_{3}}{d t_{s}^{2}}\left(\frac{e^{-\theta}}{\theta}+\frac{e^{-\theta}}{\theta^{2}}-\frac{1}{\theta^{2}}\right) \\
& \left.-\frac{d^{2} \xi_{3}}{d t_{s}^{2}}\left(\frac{e^{-\lambda \beta-\theta}}{\alpha \lambda-\beta \lambda-\theta}+\frac{e^{-\lambda \beta-\theta}-e^{-\alpha \lambda}}{(\alpha \lambda-\beta \lambda-\theta)^{2}}\right)\right]+\frac{n^{2} P^{2}}{P_{m}^{2} r^{2}} \\
& +\frac{a C_{r} n(1+n)(1+2 n) P_{s}^{4} \theta \sigma}{3\left(1-e^{-\theta}\right) P_{m}^{4} r^{2}}-\frac{2 a n\left(n^{2}-1\right) P_{s}^{3} t_{s} \lambda \varphi}{P_{m}^{3} r^{3}}>0
\end{aligned}
$$


Where, $\sigma=\frac{\lambda \alpha-1}{\lambda(\lambda \alpha-\lambda \beta-\theta)}\left(e^{-\lambda \beta-\theta}-e^{-\alpha \lambda}\right)-\frac{1}{\theta \lambda}\left(e^{-\theta}-1\right)-(\alpha-\beta)\left[e^{-\lambda \beta-\theta}-\frac{\left(e^{-\lambda \beta-\theta}-e^{-\alpha \lambda}\right)}{\lambda(\lambda \alpha-\lambda \beta-\theta)^{2}}\right]$

$$
\begin{aligned}
\varphi=\frac{h_{R} \theta}{1-e^{-\theta}} & {\left[\left(\frac{1}{\lambda^{2}}-\frac{b s}{\lambda}\right)\left(\frac{e^{-\theta}-1}{\theta}-\frac{e^{-\lambda \beta-\theta}-e^{-\lambda \alpha}}{\alpha \lambda-\beta \lambda-\theta}\right)-\frac{\beta e^{-\lambda \beta-\theta}-\alpha e^{-\lambda \alpha}}{\lambda(\alpha \lambda-\beta \lambda-\theta)}\right.} \\
& \left.-\frac{(\alpha-\beta)\left(e^{-\lambda \beta-\theta}-e^{-\lambda \alpha}\right)}{(\alpha \lambda-\beta \lambda-\theta)^{2}}\right]
\end{aligned}
$$$$
\frac{d^{2} \xi_{1}}{d t_{s}^{2}}=\frac{P_{s}^{2}}{P_{m} r^{2}}+\frac{2 P_{s}^{2}}{P_{m} r}+\frac{P_{s}^{2}\left(r^{2}-1\right)}{P_{m} r^{2}}
$$$$
\frac{d^{2} \xi_{2}}{d t_{s}^{2}}=-\frac{P_{1} P_{s}^{2}}{P_{m}^{2}}+\frac{P_{s}^{2}}{P_{m} r^{2}}+\frac{2 P_{s}^{2}}{P_{m} r}+\frac{P_{s}^{2}\left(r^{2}-1\right)}{P_{m} r^{2}}
$$$$
\frac{d^{2} \xi_{3}}{d t_{s}^{2}}=T_{R}\left[\frac{a P_{s}^{2}(r+1)(2 r+1)}{3 P_{m}^{2} r^{2}}+\frac{a P_{s}^{2}\left(r^{2}-1\right)}{6 P_{m}^{2} r}\right]+\frac{2 P_{s}}{P_{m} r}\left[\frac{P_{s}(r+1)}{2 P_{m} r}\right.
$$$$
+\frac{a P_{s}(n-r)(r+1)(2 r+1)}{6 P_{m}}+\frac{1}{6}\left(-\frac{a P_{s}(n-r)(r+1)(2 r+1)}{P_{m}}\right.
$$$$
+\frac{a P_{s}(r+1)(2 r+1)\left(\frac{1}{2} n(n+1)-\frac{1}{2}(r+1)(r+2)\right)}{P_{m} r}
$$$$
+\frac{a P_{s}\left(\frac{1}{4} n^{2}(n+1)^{2}-\frac{1}{4}(r+1)^{2}(r+2)^{2}\right)}{P_{m} r}
$$$$
\left.-\frac{a P_{s}\left(\frac{1}{3} n(n+1)(2 n+1)-\frac{1}{3}(r+1)(2 r+3)(r+2)\right)}{P_{m}}\right)
$$$$
\left.+\frac{a P_{s}^{2}(r+1)(2 r+1) t_{s}}{3 P_{m}^{2} r^{2}}+\frac{a P_{s}^{2}\left(r^{2}-1\right) t_{s}}{12 P_{m}^{2} r}+\frac{P_{s}\left(r^{2}-1\right)\left(2+\frac{a P_{s} t_{s}}{P_{m}}\right)}{12 P_{m} r}\right]
$$

This ensures that the objective function TC is minimized for $t_{s}=t_{s}^{*}$.

\section{Case 2. Production rate of the supplier $\left(P_{s}\right)$ as decision variable.}

In three-layer supply chain model, production rate of supplier is one of the most important deciding factor for inventory control. A situation in which the demand decreases (or increases) may cause the manufacturers and suppliers to decrease (or increase) their production as well. Also, the production rate may either increase or decrease with the inventory level. If the production rate of supplier increases more than the demand then it will tend the hold the inventory and increase the holding cost of the supplier. Again by producing less than the demand the supplier will deliver the raw materials with a delay to manufacturer who will have to plan his inventory accordingly to optimize his cost and reduce shortages. Therefore, in this case, we have tried to optimize the total cost of inventory of supplier, manufacturer and retailer with supplier production rate as decision variable. The problem that is interesting in this case is the production planning problem. We consider supplier produces a single product which is sold immediately to the manufacturer. The problem is presented as an optimal control problem with control variable (production rate). Typically, the firm has to balance these costs and find the quantity which should produce in order to keep the total cost minimum.

As the total cost TC is function of $P_{s}$ so we have to minimize the total cost and obtain the optimum value of the production rate for supplier taken is $\mathrm{t}_{s}^{*}$. The necessary condition for $T C\left(P_{s}\right)$ to be minimized is $\frac{d T C}{d P_{s}}=0$ and thus obtain the point $P_{s}=P_{s}^{*}$. To ensure that 
the objective function is convex for the optimal value of $P_{s}^{*}$ is such that $T C\left(P_{s}\right)$ has the minimum value if the derived value $T C^{*}\left(P_{s}^{*}\right)$ must satisfy the sufficient condition,

$$
\left.\frac{d^{2} T C}{d P_{s}^{2}}\right|_{P_{s}=P_{s}^{*}}>0
$$

Here, we have optimize the production rate of supplier to know that at what rate the supplier should produce so that the total cost is minimized and there is no shortage at manufacturer and retailer end.

Since TC is a very complicated function, with high powers in the expression, it is impossible to show the analytical validity of the above sufficient condition. Thus the inequality Eq. (12) is assessed and shown numerically.

\section{Numerical Analysis}

The production of high variety products available in supermarket with short life cycles, such as computer parts, fashion clothes, some food items and many others, has remarkably pushed different companies towards high levels of competition. To sustain in the competitive market, firms can no longer operate as individual and autonomous entities. Hence, the companies realizes the necessity of having mutual understanding and better collaboration with their suppliers, manufacturers, retailers, and customers.

So, in this paper, we have considered three layer supply chain model where suppliers, manufacturer, and retailer plan, implement and manage the flow of inventory to optimize the total cost of the inventory. Let us consider the given numerical example as below.

Example 1 In a supermarket let the retailer has price and stock dependent stochastic demand $D_{R}=a q_{i R}(t)-b s+x$ (where $a=0.8, b=5, s=30$ and $x$ is continuous random variable) based on which it orders the required amount of quantity in batches from the manufacturer considering that there is no shortages. The retailer purchase the finished good from the manufacturer at the cost of $20 \$$ per unit item and hold it at the cost of $2.1 \$$ per unit item. In order to set up infrastructure and to maintain the inventory the retailer spend $5200 \$$ per unit item. Initially when there was no product with the retailer it remains idle, which costs $4 \$$ per unit time.

Estimating the order from retailer, the manufacturer produces the required item at the rate of 0.1 units per unit time and the imperfect items are reworked at the rate of 0.2 units per unit time. The manufacturer produces the item at upto 6 cycle and in the 7th cycle the manufacturer reworked the imperfect item which is produced in the 6th cycle and remaining item in the inventory is finished by 9 th cycle. The manufacturer purchases the raw material from the supplier at the cost of $15 \$$ per unit item and holds it at the cost of $1.5 \$$ per unit item. In order to set up infrastructure and to maintain the inventory the manufacturer spend $4000 \$$ per unit item. At the 10th cycle (i.e., end of manufacturer cycle) when there is no product with the manufacturer, it remains idle which costs $3 \$$ per unit time.

The supplier based on manufacturer requirement produces the raw material at the rate of 0.15 units per unit time. The supplier purchase the raw material at the cost of $12 \$$ per unit item and hold it at the cost of $1 \$$ per unit item. In order to set up infrastructure and to maintain the inventory the manufacturer spend $3500 \$$ per unit item. At the end of supplier's inventory cycle (i.e., there is no product with the supplier) it remains idle which costs $2 \$$ per unit time. 
Data considered to illustrate the model is as below:

$$
\begin{aligned}
& \quad C_{s}=12, C_{m}=15, C_{r}=20, h_{s}=0.7, h_{m}=1.5, h_{R}=2.1, i d_{s}=2, i d_{m}=3, \\
& \quad i d_{R}=4, s=30, P_{s}=0.15, P_{m}=0.1, P_{1}=0.2, n=9, r=6, a=0.8, b=5, \\
& \theta=0.1, \lambda=0.25, A_{s}=3500, \\
& A_{m}=4000, A_{R}=5200, \text { for simplicity let us assume } k=1 .
\end{aligned}
$$

Case 1. We optimize the total cost with respect to production cycle of supplier $\left(t_{s}\right)$ (Fig. 2). Thus, we get the optimum value $T_{R}^{*}=0.352, t_{s}^{*}=1.407, t_{m}^{*}=T_{s}^{*}=2.111, T=$ 3.518 , and $T C^{*}=10700.5 \$$

\section{Sensitivity Analysis}

Sensitivity analysis is done to check the percentage change in the final cost by changing any one of the parameter by $-20 \%,-10 \%, 10 \%, 20 \%$ and keeping the other parameter fixed. Since $n$ and $r$ are integer numbers, thus we have to check the sensitivity of the parameter by changing the number of cycle by $-2,-1,1,2$.

From Table 1 and Fig. 3, we can observe that total number of cycle $(n)$ is highly sensitive. As $n$ increases the total cost decreases and vice versa. This is because as the no of cycles increases, the time for each batch delivery decreases. Manufacturer do not have to hold the inventory of items for long and for retailer due to greater availability of stock it increases the demand and which in turn decreases its holding inventory. The result of decrease in holding cost decreases the total cost and vice versa.

While for a fixed total no. of cycle $(n)$ and $n>r$, if the no. of production cycle $(r)$ decreases the total cost also decreases and it is highly sensitive. This is because for less number of production cycle the manufacturer has to produce more amount in individual cycle and it require more time to prepare the lot amount hence the total cycle time also increases. As more amount of items are produced due to the longer production run time, the rework cost, labor cost, energy cost and other costs per unit product decreases automatically and thus the total costing decreases and vice versa.

From the above Table 2 and Fig. 4, we observe that selling price (s), Retailer's purchase cost $\left(\mathrm{C}_{r}\right)$, Holding cost $\left(\mathrm{h}_{R}\right)$ are highly sensitive, Holding cost of the manufacturer $\left(\mathrm{h}_{m}\right)$ is

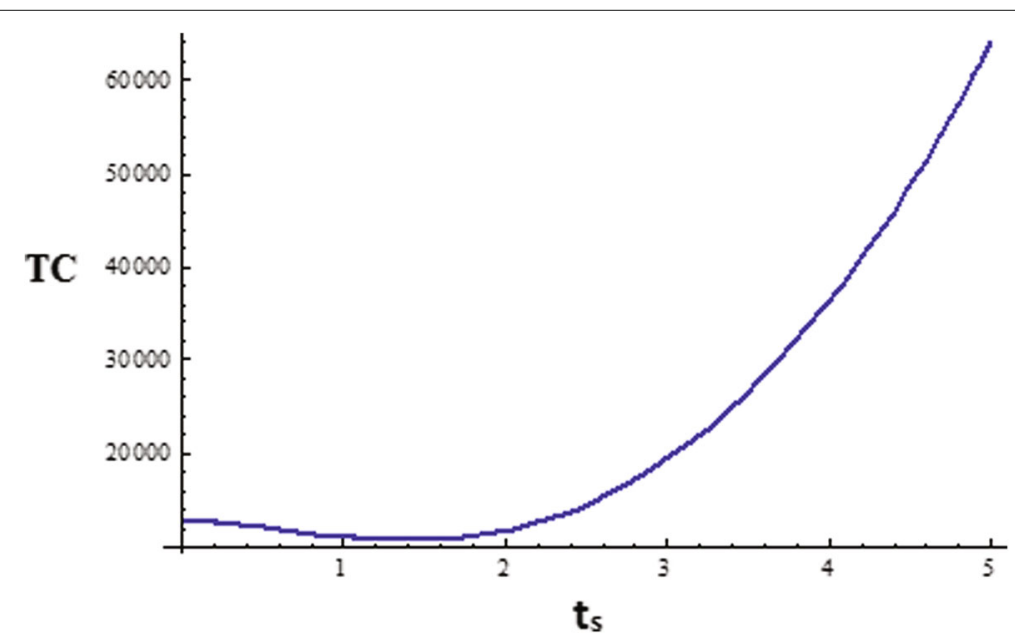

Fig. 2 Production time of the supplier $\left(\mathrm{t}_{\mathrm{s}}\right)$ vs total cost $(\mathrm{TC})$ 
Table 1 Variation of $\mathrm{n}$ and $\mathrm{r}$ with respect to TC

\begin{tabular}{|c|c|c|c|c|c|c|c|}
\hline Paramter & change & $T_{R}^{*}($ year $)$ & $t_{s}^{*}($ year $)$ & $t_{m}^{*}=T_{s}^{*}($ year $)$ & $T^{*}($ year $)$ & $T C^{*}$ & $\%$ change of TC \\
\hline & -2 & 0.311 & 1.242 & 1.863 & 2.484 & 12050.2 & 12.61 \\
\hline \multirow[t]{4}{*}{$n$} & -1 & 0.32 & 1.328 & 1.92 & 2.88 & 11509.4 & 7.56 \\
\hline & +1 & 0.369 & 1.477 & 2.216 & 4.062 & 9566.63 & -10.6 \\
\hline & +2 & 0.385 & 1.538 & 2.307 & 4.614 & 8053.92 & -24.73 \\
\hline & -2 & 0.756 & 2.017 & 3.026 & 7.564 & 1933.68 & -81.93 \\
\hline \multirow[t]{3}{*}{$r$} & -1 & 0.481 & 1.603 & 2.405 & 4.809 & 8697.96 & -18.71 \\
\hline & +1 & 0.289 & 1.348 & 2.022 & 2.889 & 11419.7 & 6.72 \\
\hline & +2 & 0.265 & 1.412 & 2.118 & 2.648 & 11666.8 & 9.03 \\
\hline
\end{tabular}

moderately sensitive, and finally purchase cost of the supplier and manufacturer $\left(\mathrm{C}_{s}\right.$ and $\left.\mathrm{C}_{m}\right)$, idle cost of the supplier, manufacturer and retailer $\left(\mathrm{id}_{s}, \mathrm{id}_{m}\right.$, and $\left.\mathrm{id}_{R}\right)$ are less sensitive. Thus, we can see that the sensitivity of various cost for the supplier and manufacturer is very less and that of retailer is very high.

(i) We observe that as selling price (s) increases, the total cost decreases. This is because the demand is price and stock dependent so if the price increases, the demand decreases which results in increase in the total cost and vice versa. We observe that this parameter is highly sensitive.

(ii) If we decrease the purchase cost $\left(\mathrm{C}_{r}\right)$ of the retailer then the total cost decreases and vice versa and it is highly sensitive, but when purchase cost $\left(C_{r}\right)$ of the retailer increases the total cost increases moderately. If purchase cost $\left(\mathrm{C}_{r}\right)$ of the retailer increases means cost of purchasing the raw material increases, so then the total cost of the retailer also increases which in turn increases the total cost of the inventory. The same is true for supplier and manufacturer but those parameters are less sensitive. That is if the purchase cost of the supplier and manufacturer $\left(C_{s}\right.$ and $\left.C_{m}\right)$ increases means cost of purchasing the raw material increases, so the total cost of the supplier and manufacturer also increases respectively, which in turn increases the total cost of the inventory.

(iii) We observe that holding cost of supplier is insensitive while that of manufacturer is less sensitive and of retailer is highly sensitive. From the table we note that if the

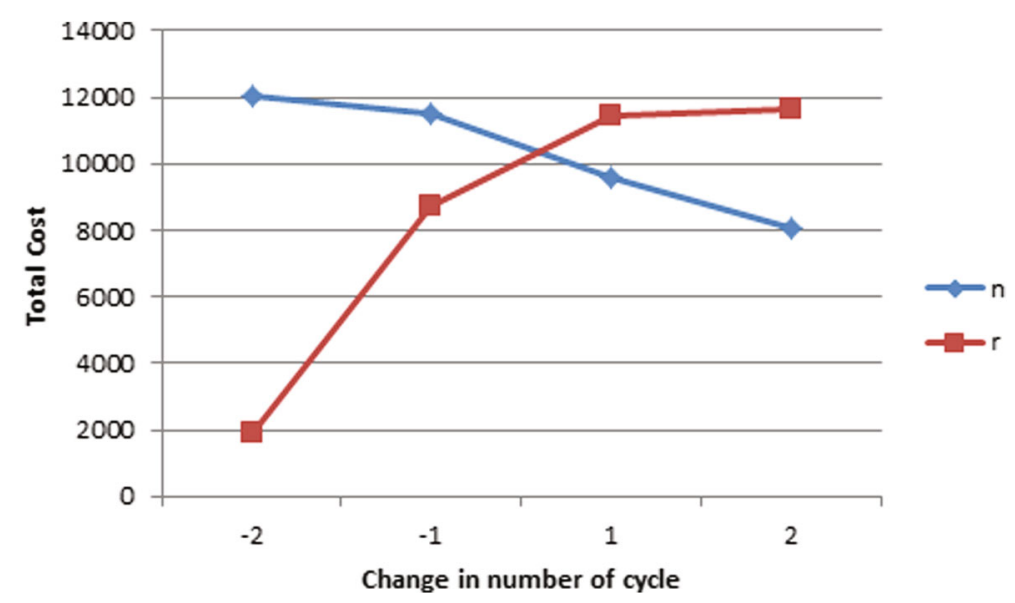

Fig. 3 Change in number of cycle vs total cost 
Table 2 Sensitivity analysis for cost parameters

\begin{tabular}{|c|c|c|c|c|c|c|c|}
\hline Paramter & $\%$ change & $T_{R}^{*}$ (year) & $t_{s}^{*}$ (year) & $t_{m}^{*}=T_{s}^{*}($ year $)$ & $T^{*}$ (year) & $T C^{*}$ & $\%$ change of TC \\
\hline & -20 & 0.226 & 0.902 & 1.353 & 2.255 & 12077.3 & 12.87 \\
\hline \multirow[t]{4}{*}{ s } & -10 & 0.286 & 1.142 & 1.713 & 2.855 & 11534.7 & 7.79 \\
\hline & 10 & 0.425 & 1.699 & 2.549 & 4.248 & 9478.1 & -11.42 \\
\hline & 20 & 0.505 & 2.021 & 3.032 & 5.053 & 7750.16 & -27.57 \\
\hline & -20 & 0.542 & 2.167 & 3.251 & 5.418 & 8001.65 & -25.22 \\
\hline \multirow[t]{4}{*}{$C_{R}$} & -10 & 0.431 & 1.723 & 2.585 & 4.308 & 9696.81 & -9.38 \\
\hline & 10 & 0.293 & 1.172 & 1.758 & 2.93 & 11328 & 5.86 \\
\hline & 20 & 0.248 & 0.991 & 1.487 & 2.478 & 11737.2 & 9.69 \\
\hline & -20 & 0.35181 & 1.40722 & 2.11083 & 3.5181 & 10699.9 & -0.006 \\
\hline \multirow[t]{4}{*}{$C_{m}$} & -10 & 0.35179 & 1.40717 & 2.11076 & 3.5179 & 10700.2 & -0.003 \\
\hline & 10 & 0.35177 & 1.40707 & 2.11062 & 3.5177 & 10700.9 & 0.004 \\
\hline & 20 & 0.35176 & 1.40704 & 2.11056 & 3.516 & 10701.2 & 0.007 \\
\hline & -20 & 0.3518 & 1.4072 & 2.1108 & 3.518 & 10700 & -0.005 \\
\hline \multirow[t]{4}{*}{$C_{s}$} & -10 & 0.35179 & 1.40716 & 2.11074 & 3.5179 & 10700.3 & -0.002 \\
\hline & 10 & 0.35177 & 1.40709 & 2.11063 & 3.51772 & 10700.8 & 0.003 \\
\hline & 20 & 0.35176 & 1.40705 & 2.11057 & 3.51762 & 10701.1 & 0.006 \\
\hline & -20 & 0.214 & 0.857 & 1.286 & 2.143 & 12148.6 & 13.53 \\
\hline \multirow[t]{4}{*}{$h_{R}$} & -10 & 0.279 & 1.115 & 1.673 & 2.788 & 11596.7 & 8.38 \\
\hline & 10 & 0.435 & 1.740 & 2.610 & 4.350 & 9316.04 & -12.94 \\
\hline & 20 & 0.531 & 2.123 & 3.185 & 5.308 & 7248.56 & -32.26 \\
\hline & -20 & 0.373 & 1.492 & 2.238 & 3.730 & 10421.3 & -2.61 \\
\hline \multirow[t]{4}{*}{$h_{m}$} & -10 & 0.362 & 1.449 & 2.174 & 3.623 & 10565.4 & -1.26 \\
\hline & 10 & 0.342 & 1.367 & 2.051 & 3.418 & 10827.2 & 1.18 \\
\hline & 20 & 0.332 & 1.328 & 1.992 & 3.32 & 10946.1 & 2.3 \\
\hline & -20 & 0.352 & 1.4072 & 2.1108 & 3.518 & 10700.1 & -0.004 \\
\hline \multirow[t]{4}{*}{$i d_{r}$} & -10 & 0.352 & 1.4072 & 2.1108 & 3.518 & 10700.3 & -0.002 \\
\hline & 10 & 0.35178 & 1.4071 & 2.11065 & 3.5178 & 10700.7 & 0.002 \\
\hline & 20 & 0.35178 & 1.4071 & 2.11065 & 3.5178 & 10701 & 0.005 \\
\hline & -20 & 0.35183 & 1.4073 & 2.11095 & 3.5183 & 10699.3 & -0.011 \\
\hline \multirow[t]{4}{*}{$i d_{m}$} & -10 & 0.352 & 1.4072 & 2.1108 & 3.518 & 10699.9 & -0.006 \\
\hline & 10 & 0.35175 & 1.407 & 2.1105 & 3.5175 & 10701.2 & 0.007 \\
\hline & 20 & 0.35173 & 1.4069 & 2.11035 & 3.5173 & 10701.8 & 0.012 \\
\hline & -20 & 0.352 & 1.4072 & 2.1108 & 3.518 & 10700 & -0.005 \\
\hline \multirow[t]{3}{*}{$i d_{r}$} & -10 & 0.352 & 1.4072 & 2.1108 & 3.518 & 10700.3 & -0.002 \\
\hline & 10 & 0.35178 & 1.4071 & 2.11065 & 3.5178 & 10700.8 & 0.003 \\
\hline & 20 & 0.35175 & 1.407 & 2.1105 & 3.5175 & 10701.1 & 0.006 \\
\hline
\end{tabular}
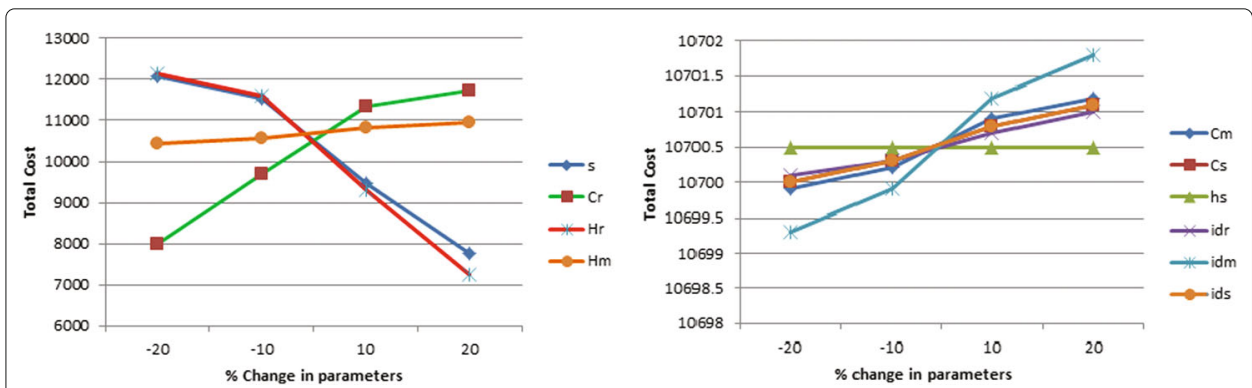

Fig. 4 Percentage change of cost parameter vs percentage change of total cost 
holding cost of manufacturer increases then the total cost also increases. This is true in reality because the manufacturer has to hold the item which it produces and thus the total costing of manufacturer increases and hence the total inventory cost increases. But, if the holding cost of retailer increases then the total cost also decreases. This is because the demand of the retailer is price and stock dependent and so to optimize the retailer try to keep less stock thus the total cost of the retailer decreases which in turn decreases the total costing of the inventory.

(iv) The idle cost of the supplier, manufacturer and retailer are very less sensitive. This has positive effect in our model since idle time means wastage of resources because machinery are idle and it is not in use. So, this means we can use this time for repairing machinery default, if any, by not effecting to inventory costing.

From Table 3 and Fig. 5, we observe that production rate of supplier $\left(\mathrm{P}_{s}\right)$, manufacturer $\left(\mathrm{P}_{m}\right)$ and the rework rate of the manufacturer $\left(\mathrm{P}_{1}\right)$, and demand factor $(\mathrm{b})$ are highly sensitive. The demand factor $(\mathrm{a})$, parameter $(\theta)$, and $(\lambda)$ are moderately sensitive.

(i) We observe that as the production rate of the supplier $\left(\mathrm{P}_{s}\right)$ increases the total cost of the inventory also increases and vice versa. This is true because supplier will produce more item in short time and thus the overall costing increases also once the item is produced it is transferred to the manufacturer where latter has to hold the item for longer time. Thus, considering all the effects, the total inventory cost increases. The

Table 3 Sensitivity analysis for various parameters

\begin{tabular}{|c|c|c|c|c|c|c|c|}
\hline Paramter & \% change & $T_{R}^{*}($ year $)$ & $t_{s}^{*}$ (year) & $t_{m}^{*}=T_{s}^{*}($ year $)$ & $T^{*}($ year $)$ & $T C^{*}$ & $\%$ change of TC \\
\hline & -20 & 0.806 & 4.032 & 4.838 & 8.06 & 3170.33 & -70.37 \\
\hline \multirow[t]{4}{*}{$P_{s}$} & -10 & 0.513 & 2.282 & 3.081 & 5.135 & 8583.53 & -19.78 \\
\hline & 10 & 0.255 & 0.926 & 1.528 & 2.54 & 11641.7 & 8.79 \\
\hline & 20 & 0.192 & 0.6397 & 1.151 & 1.919 & 12104.5 & 13.12 \\
\hline & -20 & 0.118 & 0.378 & 0.709 & 1.181 & 12505.6 & 16.87 \\
\hline \multirow[t]{4}{*}{$P_{m}$} & -10 & 0.21 & 0.755 & 1.258 & 2.097 & 12020.8 & 13.34 \\
\hline & 10 & 0.564 & 2.483 & 3.386 & 5.643 & 7470.6 & -30.18 \\
\hline & 20 & 0.859 & 4.123 & 5.154 & 8.589 & 435.84 & -95.93 \\
\hline & -20 & 0.712 & 2.85 & 4.275 & 7.125 & 2904.13 & -72.86 \\
\hline \multirow[t]{4}{*}{$P_{1}$} & -10 & 0.486 & 1.944 & 2.916 & 4.86 & 8529.98 & -20.28 \\
\hline & 10 & 0.263 & 1.052 & 1.578 & 2.63 & 11684.7 & 9.2 \\
\hline & 20 & 0.199 & 0.799 & 1.199 & 1.998 & 12173.6 & 13.77 \\
\hline & -20 & 0.255 & 1.018 & 1.527 & 2.545 & 12030.2 & 12.43 \\
\hline \multirow[t]{4}{*}{$a$} & -10 & 0.307 & 1.229 & 1.844 & 3.073 & 11443.9 & 6.95 \\
\hline & 10 & 0.3898 & 1.559 & 2.339 & 3.898 & 9822.67 & -8.2 \\
\hline & 20 & 0.423 & 1.690 & 2.535 & 4.225 & 8830.38 & -17.48 \\
\hline & -20 & 0.226 & 0.902 & 1.353 & 2.255 & 12077.3 & 12.87 \\
\hline \multirow[t]{4}{*}{$b$} & -10 & 0.286 & 1.142 & 1.713 & 2.855 & 11534.7 & 7.79 \\
\hline & 10 & 0.425 & 1.699 & 2.549 & 4.248 & 9478.1 & -11.42 \\
\hline & 20 & 0.505 & 2.021 & 3.032 & 5.053 & 7750.16 & -27.57 \\
\hline & -20 & 0.272 & 1.086 & 1.629 & 2.715 & 11608.4 & 8.48 \\
\hline \multirow[t]{4}{*}{$\theta$} & -10 & 0.313 & 1.251 & 1.877 & 3.128 & 11179.1 & 4.47 \\
\hline & 10 & 0.389 & 1.556 & 2.334 & 3.89 & 10180 & -4.86 \\
\hline & 20 & 0.424 & 1.697 & 2.546 & 4.243 & 9623.54 & -10.06 \\
\hline & -20 & 0.226 & 0.904 & 1.356 & 2.26 & 11862.2 & 10.86 \\
\hline \multirow[t]{3}{*}{$\lambda$} & -10 & 0.285 & 1.138 & 1.707 & 2.845 & 11370 & 6.26 \\
\hline & 10 & 0.429 & 1.717 & 2.576 & 4.293 & 9811.75 & -8.31 \\
\hline & 20 & 0.517 & 2.067 & 3.101 & 5.168 & 8664.94 & -19.02 \\
\hline
\end{tabular}




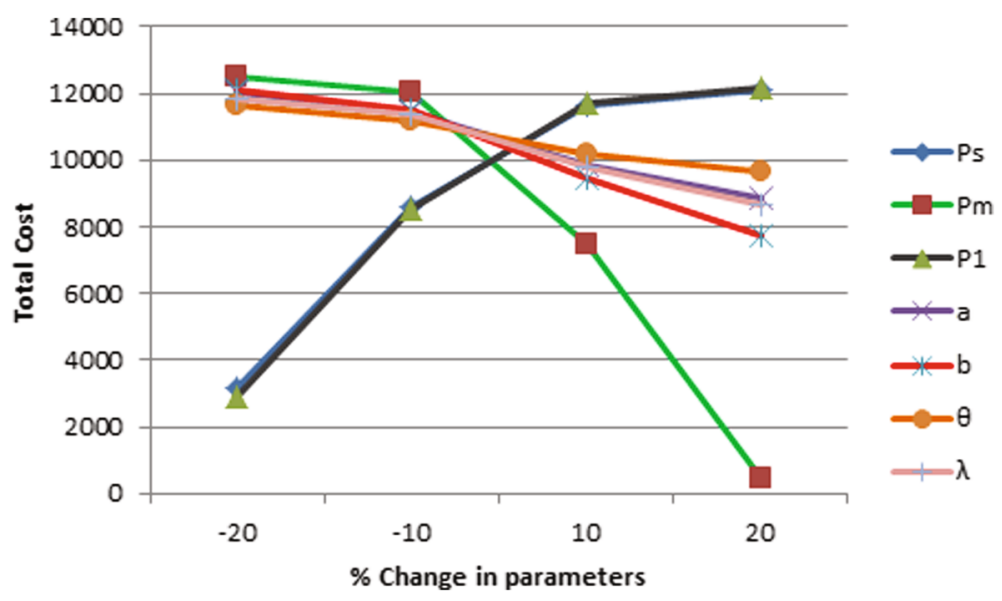

Fig. 5 Percentage changes of parameters vs change of total cost

same is true for the production rate of the rework item $\left(\mathrm{P}_{1}\right)$, i.e., if $\mathrm{P}_{1}$ increases the total cost of the inventory also increases. This is true because manufacturer will produce more reworked item in short time then the machinery costing increases. While if the production rate of the manufacturer decreases then the total cost increases. This is true since the demand of the retailer is price- and stock-dependent so if the manufacturer take more time to produce the finished item then there is a gap in supply from manufacturer to retailer or a chance of shortage which result to increase in the total cost.

(ii) We observe from the table that as the demand parameters ( $a$ and $b$ ) increases the total cost increase and vice versa. This holds in reality because if we have more stock and if the price of the item are increased then the demand decreases thus the total costing increases.

(iii) As $\theta$ increases the total cost decreases moderately. As $\theta$ increases then $g(\mathrm{z})$ decreases means rate of defective item decreases which in turn decreases the total inventory costing.

(iv) As $\lambda$ increases the total cost decreases moderately. As $\lambda$ increases then $f(z)$ decreases means demand decreases which in turn decreases the total inventory costing.

Case 2. We optimizes the total cost by considering the production rate $P_{s}$ as the decision variable (Fig. 6).

Here we have considered $t_{s}=2$, then the optimized total cost $T C^{*}=7165.85$ and $P_{s}^{*}=$ 0.11 . We obtain the graph as:

\section{Supply-Demand Relation}

Since our model is a three layer supply chain system so a supply demand relation should be maintained, i.e, item should be produced in such a quantity that it should satisfy the demand and there is no shortages. A supply chain is made up by multiple actors, multiple flows of items, information and finances. Each network node has its own customers' and suppliers' management strategies, demand arrival process and demand forecast methods, inventory control policies and items mixture. In real life scenarios, 


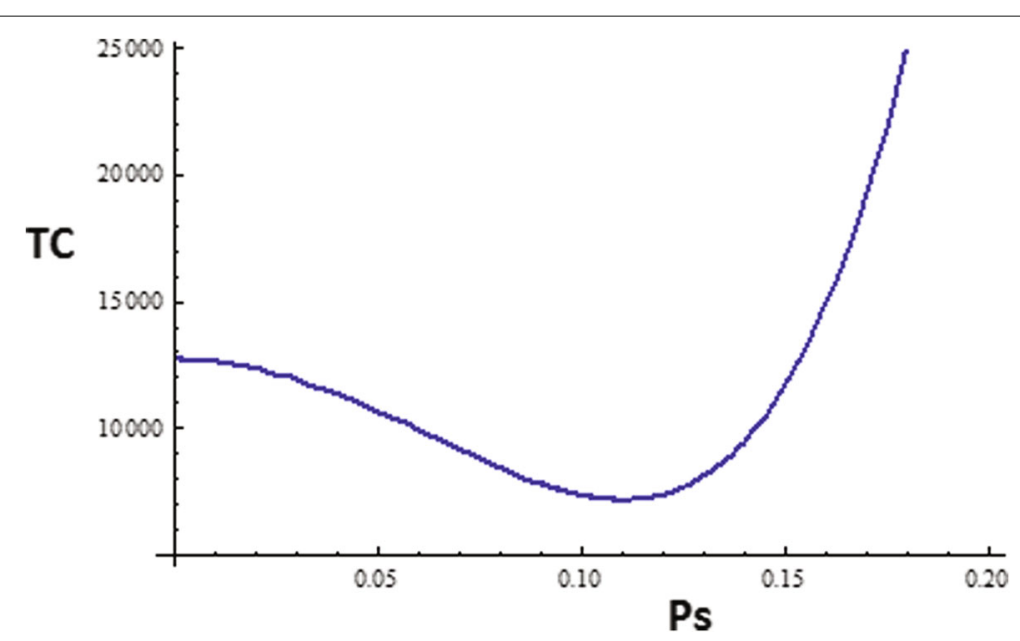

Fig. 6 Production rate of supplier $\left(P_{s}\right)$ vs total inventory cost $(T C)$

it is often observed there are imbalances in supply and demand of items which results in loss of business and profit simultaneously. It is very difficult for the manufacturer to predict the stochastic demand and plan its raw material accordingly to meet the orders deadline. Again suppliers has its own limitation of production capacity with which it can deliver its order in required time limit. So, here we have tried to draw a relationship between the stochastic demand of the retailer and the production rate of supplier so that we can optimize the inventory in such a way keeping in mind the limitations of supplier's end (observe Fig. 7).

Thus quantity produced by the manufacturer $=\sum_{i=1}^{n} \int_{i T_{R}}^{(i+1) T_{R}} D(t, x) d t$

The number of items produced from the raw material of the supplier $=k P_{s} t_{s}$ Thus , $k P_{s} t_{s}=\sum_{i=1}^{n} \int_{i T_{R}}^{(i+1) T_{R}} D(t, x) d t$

Solving the above equation we get $P_{s}=\frac{2 k r^{2} P_{m}^{2}}{(x-b s)(a-1) n^{2} t_{s}}$

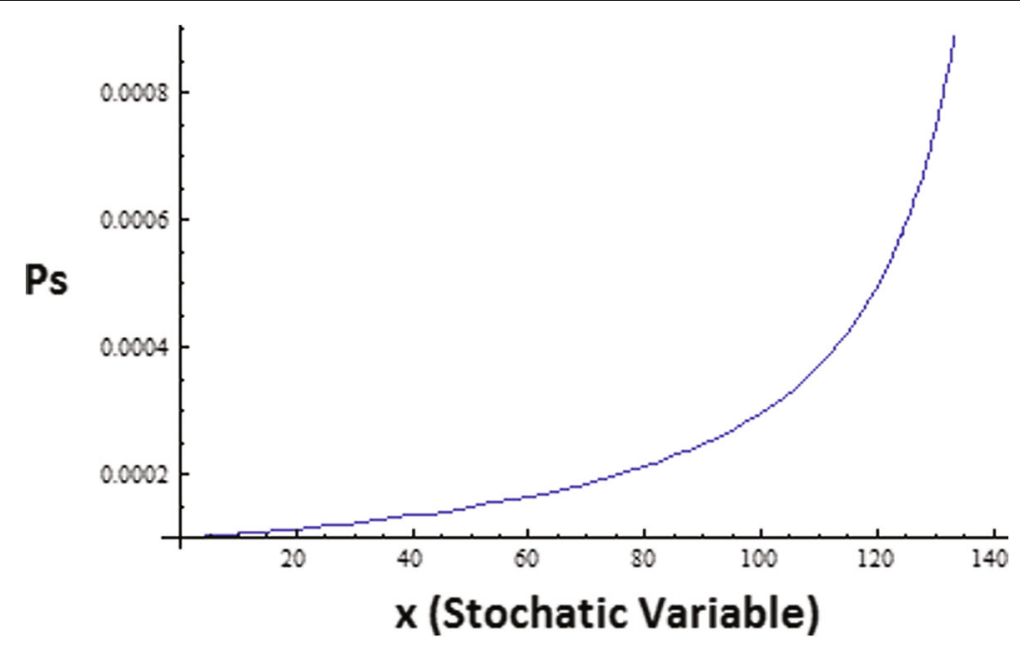

Fig. 7 Stochastic variable $(\mathrm{x})$ vs production rate of supplier $\left(P_{S}\right)$ 


\section{Conclusions}

Supply chain optimization is a modern subject. Here, we have not just focused on the retailer's cost, but examined costs in three layers of supply chain. In this paper, we have optimized the whole supply chain, and make it more effective and efficient. Production quality of a supply chain directly effect the coordination of the product flow within a supply chain. Thus, dealing with imperfect items have become an important and growing area of research. The model can be used in textile industries, footwear, chemical, food, cosmetics, etc. where the defective items will be produced in each cycle of production. In our paper, we have assumed that the produced lot at each stage is sent to the subsequent stages in two ways: firstly from supplier to manufacturer where shipments are sent as soon as they are produced and there is no need to wait until a whole lot is produced and secondly from manufacturer to retailer in variable shipment (depend upon customer's demand). This policy leads to considerable savings as compared to the scheme that allows shipments only after the whole lot is produced. In the numerical example, we have formulated and accounted for all the cost in each layer and tried to optimize the total cost with two decision variables $t_{s}$ (production time of the supplier) and $P_{s}$ (production rate of the supplier) in two separate cases. From the sensitivity analysis in case 1 , we have found that the total cost of supplier is less sensitive, manufacturer is moderately sensitive and retailer is highly sensitive to various parameters. It is also observed from the analysis that not only production rate of supplier and manufacturer can be a decisive factor in optimizing the total cost of inventory, but also the purchase cost, holding cost and sale price of item for retailer can be a major breakthrough in expanding the profit of business in real terms. The major aim of the work presented in this paper is to provide a cost-effective approach that would enable organizations to compete in the global market by coordinating the supplier, manufacturer and retailer when the demand is uncertain. Also reworking the imperfect item is essential. In our paper we observe that it would be better to rework at slower rate which indirectly means less amount of defective item are produced by manufacturer. It is also observed that if the demand increases the supplier has to produce more item but upto certain rate so that the total cost is minimum. Since from case 2 we observe that if the production rate of supplier is increased, the total cost first decreases then it increases. The researchers can work more by considering the effect of shortages and backordered or can consider the effect of inspection error.

Authors' Contributions

GM proposed the framework of the study. SP drafted the manuscript, conceived the study, and participated in its design and coordination. GS participated in the critical analysis of the study. All authors read and approved the final manuscript.

Competing Interests

The authors declare that they have no competing interests.

\section{Author details}

${ }^{1}$ Department of Mathematics, Techno India University, West Bengal, India. ${ }^{2}$ Department of Mathematics, National Institute of Technology Puducherry, Karaikal 609605 , India. ${ }^{3}$ Department of Mathematics, Indian Institute of Engineering Science and Technology, Shibpur, Howrah 711103, India.

Received: 8 July 2016 Accepted: 5 October 2016

Published online: 28 October 2016

References

1. Abdelsalam, HM, Elassal, MM: Joint economic lot sizing problem for a three-layer supply chain with stochastic demand. Int. J. Prod. Econ (2014). doi:10.1016/j.ijpe.2014.01.015 (under press)

2. Alshamrani, AM: Optimal control of a stochastic production-inventory model with deteriorating items. J. King Saud Univ. Sci. 25(1), 7-13 (2013) 
3. Ben-Daya, M, Al-Nassar, A: An integrated inventory production system in a three layer supply chain. Prod. Plan. Control. 19(2), 97-104 (2008)

4. Ben-Daya, M, Darwish, M, Ertogal, K: The joint economic lot-sizing problem: review and extensions. Eur. J. Oper. Res. $185,726-742(2008)$

5. Ben-Daya, M, Hassini, E, Hariga, M, Al Durgama, M: Consignment and vendor managed inventory in single-vendor multiple buyers supply chains. Int. J. Prod. Res. 51(5), 1347-1365 (2013)

6. Browne, S, Paul, Z: Inventory models with continuous, stochastic demands. Ann. Appl. Probab. 1(3), 419-435 (1991)

7. Chen, S, Geunes, J: Optimal allocation of stock levels and stochastic customer demands to a capacitated resource. Ann. Oper. Res. 203, 33-54 (2013)

8. Chiu, YP: Determining the optimal lot size for the finite production model with random defective rate, the rework process, and backlogging. Eng. Optim. 35(4), 427-437 (2003)

9. Dellaert, NP, Melo, MT: Heuristic procedures for a stochastic lot-sizing problem in make-to-order manufacturing. Ann. Oper. Res. 59, 227-258 (1995)

10. El-Kassar, AN: Optimal order quantity for imperfect quality items. Proc. Acad. Inf. Manag. Sci. 13(1), 24-30 (2009)

11. El-Kassar, AN, Salameh, M, Bitar, M: EPQ model with imperfect quality items of raw material and finished product. Proceedings the Academic and Business Research Institute Conference, Orlando, Florida (2012)

12. Goyal, SK: An integrated inventory model for a single supplier-single customer problem. Int. J. Prod. Res. 15, 107-111 (1977)

13. Goyal, SK: A one-vendor multi-buyer integrated inventory model a comment. Eur. J. Oper. Res. 82, 209-210 (1995)

14. Gumus, AT, Guneri, AF: A multi-echelon inventory management framework for stochastic and fuzzy supply chains. Expert Syst. Appl. 36(3-1), 5565-5575 (2009)

15. Hayek, PA, Salameh, MK: Production lot sizing with the reworking of imperfect quality items produced. Prod. Plan. Control. 12(6), 584-590 (2001)

16. He, Y, Zhao, X, Zhao, L, He, J: Coordinating a supply chain with effort and price dependent stochastic demand. Appl. Math. Model. 33(6), 2777-2790 (2009)

17. Hill, RM: The single vendor and single buyer integrated production inventory model with a generalized policy. Eur. J. Oper. Res. 97, 493-499 (1997)

18. Hoque, MA: An optimal solution technique to the single-vendor multi-buyer integrated inventory supply chain by incorporating some realistic factors. Eur. J. Oper. Res. 215(1), 80-88 (2011)

19. Huang, CK, Tsai, DM, Wu, JC, Chung, KJ: An optimal integrated vendor-buyer inventory policy under conditions of order-processing time reduction and permissible delay in payments. Int. J. Prod. Econ. 128, 445-451 (2010)

20. Jaber, MY, Zanoni, S, Zavanella, LE: Economic order quantity models for imperfect items with buy and repair options. Int. J. Prod. Econ. 155, 126-131 (2014)

21. Jana, DK, Maity, K, Roy, TK: A three-layer supply chain integrated production-inventory model under permissible delay in payments in uncertain environments. J. Uncertainty Anal. Appl (2013). doi:10.1186/2195-5468-1-6

22. Jha, JK, Shanker, K: Single-vendor multi-buyer integrated production-inventory model with controllable lead time and service level constraints. Appl. Math. Model. 37(4), 1753-1767 (2013)

23. Khan, M, Jaber, MY, Guiffrida, AL, Zolfaghari, S: A review of the extensions of a modified EOQ model for imperfect quality items. Int. J. Prod. Econ. 132(1), 1-12 (2011)

24. Kumar, M, Chauhan, A, Kumar, P: Economic production lot size model with stochastic demand and shortage partia backlogging rate under imperfect quality items. Int. J. Adv. Sci. Technol. 31, 1-22 (2011)

25. Lam, CY, Ip, WH: A customer satisfaction inventory model for supply chain integration. Expert Syst. Appl. 38(1), 875-883 (2011)

26. Liao, GL, Sheu, SH: Economic production quantity model for randomly failing production process with minimal repair and imperfect maintenance. Int. J. Prod. Econ. 130, 118-124 (2011)

27. Liberopoulos, G, Pandelis, DG, Hatzikonstantinou, O: The stochastic economic lot sizing problem for non-stop multi-grade production with sequence-restricted setup changeovers. Ann. Oper. Res. 209, 179-205 (2013)

28. Lieckens, K, Vandaele, N: Differential evolution to solve the lot size problem in stochastic supply chain management systems. Ann. Oper. Res (2015). doi:10.1007/s10479-014-1778-0

29. Lin, CC, Wu, YC: Combined pricing and supply chain operations under price-dependent stochastic demand. Appl. Math. Model. 38(5-6), 1823-1837 (2014)

30. Lin, YJ, Ouyang, LY, Dang, YF: A joint optimal ordering and delivery policy for an integrated supplier-retailer inventory model with trade credit and defective items. Appl. Math. Comput. 218(14), 7498-7514 (2012)

31. Manna, AK, Dey, JK, Mondal, SK: Three-layer supply chain in an imperfect production inventory model with two storage facilities under fuzzy rough environment. J. Uncertainty Anal. Appl (2014). doi:10.1186/s40467-014-0017-1

32. Pal, B, Sana, SS, Chaudhuri, KS: A mathematical model on EPQ for stochastic demand in an imperfect production system. J. Manuf. Syst. 32(1), 260-270 (2013)

33. Pal, S, Mahapatra, GS, Samanta, GP: An inventory model of price and stock dependent demand rate with deterioration under inflation and delay in payment. Int. J. Syst. Assur. Eng. Manag. 5(4), 591-601 (2014)

34. Pasandideh, SHR, Niaki, STA, Asadi, K: Optimizing a bi-objective multi-product multi-period three echelon supply chain network with warehouse reliability. Expert Syst. Appl. 42(5), 2615-2623 (2015)

35. Pasandideh, SHR, Niaki, STA, Tokhmehchi, N: A parameter-tuned genetic algorithm to optimize two-echelon continuous review inventory systems. Expert Syst. Appl. 38(9), 8-11714 (2011)

36. Prasad, K, Mukherjee, B: Optimal inventory model under stock and time dependent demand for time varying deterioration rate with shortages. Ann. Oper. Res (2014). doi:10.1007/s10479-014-1759-3

37. Ramakrishna, KS, Sharafali, M, Lim, YF: A two-item two-warehouse periodic review inventory model with transhipment. Ann. Oper. Res (2013). doi:10.1007/s10479-013-1483-4

38. Salameh, MK, Jaber, MY: Economic production quantity model for items with imperfect quality. Int. J. Prod. Econ. 64, 59-64 (2000)

39. Sana, SS: An economic production lot size model in an imperfect production system. Eur. J. Oper. Res. 201, 158-170 (2010) 
40. Sana, SS: A production-inventory model of imperfect quality products in a three layer supply chain. Decis. Support. Syst. 50, 539-547 (2011)

41. Sana, SS: An EOQ model for stochastic demand for limited capacity of own warehouse. Ann. Oper. Res (2013). doi:10.1007/s10479-013-1510-5

42. Sarkar, BR, Diponegoro, A: Optimal production plans and shipment schedules in a supply-chain system with multiple suppliers and multiple buyers. Eur. J. Oper. Res. 194, 753-773 (2009)

43. Sarkar, B, Sarkar, S: An improved inventory model with partial backlogging, time varying deterioration and stock-dependent demand. Econ. Model. 30, 924-932 (2013)

44. Solyal, $\mathrm{O}$, Sural, $\mathrm{H}$ : The one-warehouse multi-retailer problem: reformulation, classification, and computational results. Ann. Oper. Res. 196, 517-541 (2012)

45. Soni, HN, Patel, KA: Optimal strategy for an integrated inventory system involving variable production and defective items under retailer partial trade credit policy. Decis. Support. Syst. 54(1), 235-247 (2012)

46. Srinivas, C, Rao, CSP: Optimization of supply chains for single-vendor-multibuyer consignment stock policy with genetic algorithm. Int. J. Adv. Manuf. Technol. 48, 407-420 (2010)

47. Ting, PS, Chung, KJ: Remarks on the optimization method of a manufacturing system with stochastic breakdown and rework process in supply chain management. Appl. Math. Model. 38(7-8), 2290-2295 (2014)

48. Varyani, A, Jalilvand-Nejad, A, Fattahi, P: Determining the optimum production quantity in three-echelon production system with stochastic demand. The Int. J. Adv. Manuf. Technol. 72(1-4), 119-133 (2014)

49. Zavanella, L, Zanoni, S: A one-vendor multi-buyer integrated production-inventory model: The Consignment Stock case. Int. J. Prod. Econ. 118, 225-232 (2009)

50. Zavanella, L, Zanoni, S: Erratum to 'A one-vendor multi-buyer integrated production-inventory model: the "Consignment Stock" case'. Int. J. Prod. Econ. 125(1), 212-213 (2010)

51. Zhou, Z, Guan, Y: Two-stage stochastic lot-sizing problem under cost uncertainty. Ann. Oper. Res. 209, 207-230 (2013)

\section{Submit your manuscript to a SpringerOpen ${ }^{\circ}$ journal and benefit from:}

- Convenient online submission

- Rigorous peer review

- Immediate publication on acceptance

- Open access: articles freely available online

- High visibility within the field

Retaining the copyright to your article

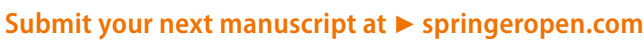

